\title{
Prevention of PONV by acustimulation with cap- sicum plaster is comparable to ondansetron after middle ear surgery
}

\author{
[La prépention des NVPO par acustimulation avec un emplâtre de Capsicum est \\ comparable à celle de l'ondansétron après une opération à l'oreille moyenne]
}

Mahender Nath Misra MS, Asok Jayaraj Pullani MBbs, Zubair Umer Mohamed MBвs

Purpose: To compare the efficacy of stimulation of P6 acupoint with capsicum plaster in comparison with iv ondansetron for the prevention of postoperative nausea and vomiting (PONV).

Methods: I 20 patients of either sex, ASA I-II, undergoing elective middle ear surgeries under general anesthesia were included in this randomized, prospective, double-blinded and placebo-controlled study. The anesthetic technique was standardized. Patients were divided into three groups. Group I was the control group. Capsicum plaster $(\mathrm{I} \times \mathrm{I} \mathrm{cm})$ was affixed at the $\mathrm{P} 6$ acupoint on both forearms 30 min before induction of anesthesia in patients of Group II. Patients of Groups I and III received an inactive adhesive plaster at the same site. Ondansetron $4 \mathrm{mg}$ iv was given to patients of Group III at the end of surgery and the rest of the patients received a placebo. The plasters were removed six hours after transferring the patients to the postoperative unit. Criteria were fixed for the administration of rescue antiemetics (ondansetron $4 \mathrm{mg}$ iv). PONV and the requirement for rescue antiemetics were recorded by a blinded observer.

Results: The incidence of PONV and the requirement for rescue antiemetics were significantly lower in both the acustimulation and ondansetron groups at six hours. At $24 \mathrm{hr}$ there was a reduction in the requirement for rescue medication in the ondansetron group.

Conclusion: Stimulation of the P6 acupoint with capsicum plaster is an effective method for prevention of PONV after middle ear surgery and its efficacy is comparable to ondansetron for the first six hours after surgery.
Objectif : Comparer l'efficacité de la stimulation de l'acupoint P6 avec un emplâtre de Capsicum et l'administration iv d'ondansétron pour la prévention des nausées et vomissements postopératoires (NVPO).

Méthode : Cent vingt hommes et femmes, d'état physique ASA I-II, devant subir une opération de l'oreille moyenne sous anesthésie générale, ont participé à l'étude randomisée, prospective, à double insu et contrôlée par placebo. La technique anesthésique a été normalisée. Les patients ont été répartis en trois groupes. Le groupe l était le groupe témoin. Un emplâtre de Capsicum $(I \times I \mathrm{~cm})$ a été appliqué à l'acupoint P6 sur les deux avant-bras $30 \mathrm{~min}$ avant l'induction de l'anesthésie chez les patients du groupe II. Les patients des groupes I et III ont reçu un emplâtre adhésif inactif au même site. Une dose de 4 mg d'ondansétron iv a été administrée aux patients du groupe III à la fin de l'opération et le reste des patients a reçu un placebo. Les emplâtres ont été enlevés six heures après le transfert à l'unité des soins postopératoires. Les critères ont été fixés pour l'administration d'antiémétiques de secours (4 mg d'ondansétron iv). Les NVPO et les demandes d'antiémétiques ont été notées par un observateur neutre.

Résultats : À six heures, l'incidence de NVPO et les demandes d'antiémétiques étaient significativement plus basses avec l'acustimulation et l'ondansétron. À 24 h, il y a eu une réduction des demandes de médicaments de secours chez ceux qui avaient reçu l'ondansétron.

Conclusion : La stimulation de l'acupoint P6 avec un emplâtre de Capsicum est aussi efficace que l'ondansétron pendant les six premières heures postopératoires pour prévenir les NVPO après une opération de l'oreille moyenne.

From the Department of Anesthesioogy, M.L.N. Medical College and Associated Hospitals, Allahabad, India. Address correspondence to: Dr. Asok Jayaraj Pullani, 103, New PG Hostel, SRN Hospital, Allahabad, UP, India, PIN 211001. Phone: +91-933-5150468; E-mail: ashokjayaraj@yahoo.com

The study was supported financially by the authors. Accepted for publication November 25, 2004. Revision accepted February 18, 2005. 
$\mathrm{P}$

OSTOPERATIVE nausea and vomiting (PONV) are frequent sequelae in patients undergoing middle ear surgeries. These are unpleasant experiences for patients and occasionally can lead to serious complications. The incidence of PONV can be as high as 62 to $80 \%$ when no prophylactic antiemetic has been given. ${ }^{1-3}$ Various drugs have been found to be effective in decreasing PONV but have their own adverse effects. Selective serotonin antagonists now form the mainstay in the prevention and treatment of PONV, but even they have limited effects. A multimodal approach has been recommended recently which involves identifying high risk groups, use of an anesthetic technique least likely to cause vomiting and administration of a combination of antiemetics. ${ }^{4}$ The high cost of drugs becomes a major factor limiting their routine use. ${ }^{5}$

The antiemetic effect of stimulation of the $\mathrm{P} 6 \mathrm{acu}^{-}$ point by various methods has been established. ${ }^{6}$ The need of a person trained in acupuncture, costly equipment for electrical stimulation and the availability of acupressure wristbands may limit their use. Recently Kim et al. described the use of a capsicum plaster for the prevention of PONV after abdominal hysterectomy. ${ }^{7}$ This seems to be a simple, inexpensive and easily available method, but its role has not been fully evaluated. We undertook a study to compare the efficacy of capsicum plaster at P6 acupoint with ondansetron to prevent PONV in patients undergoing middle ear surgeries under general anesthesia.

\section{Methods}

The study was approved by the Ethical Committee of the hospital and Allahabad University. Informed consent was obtained from all the patients included in the study. One hundred and twenty patients of either sex aged 18 to $52 \mathrm{yr}$, ASA I-II, undergoing middle ear surgery were included in this study. Exclusion criteria included pregnant women, obesity, diabetes mellitus, impaired renal or liver functions, patients who had taken $\mathrm{H} 2$ antagonists, antiemetic or psychoactive medication or had nausea, retching or vomiting within 48 $\mathrm{hr}$ before surgery. The patients provided detailed medical histories and demographic information including age, weight, last menstrual period and previous history of PONV or motion sickness. The subjects were randomly assigned to one of the three groups using a computer-generated random number table.

All patients received lorazepam $2 \mathrm{mg}$ po the night before surgery and the P6 acupoint was marked out on both forearms. The P6 or "Nei-guan" acupoint is located on the anterior aspect of the forearm two body inches proximal to the most distal skin crease of the

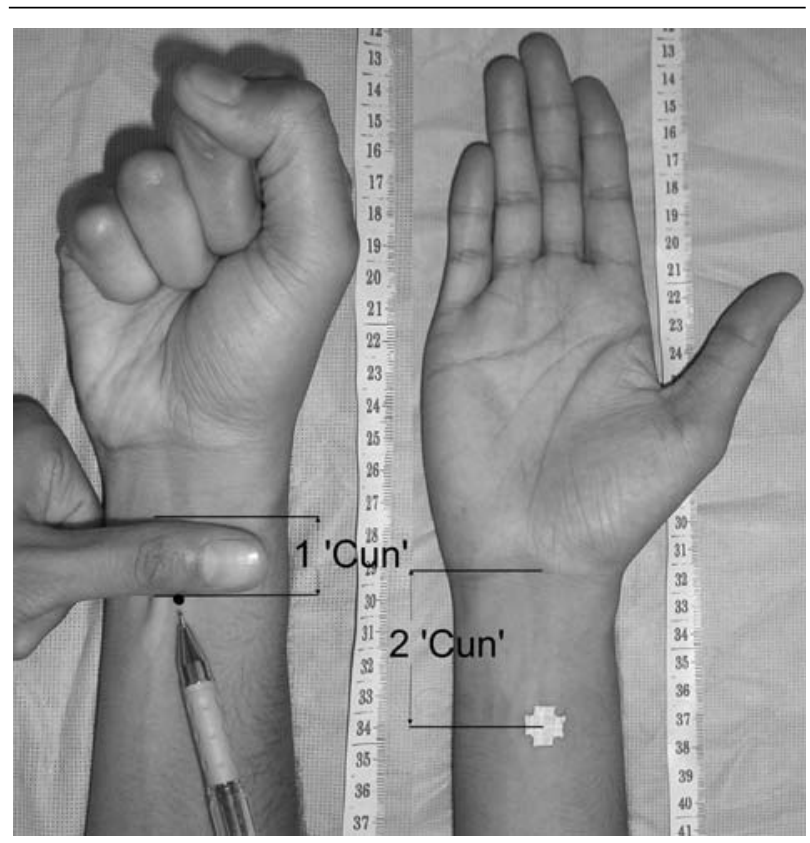

FIGURE Location of the P6 acupoint (left) and capsicum plaster $(1 \times 1 \mathrm{~cm})$ affixed to the $\mathrm{P} 6$ acupoint (right).

wrist joint, between the tendons of flexor carpi radialis and palmaris longus. One body inch or "cun" is the width of the patient's thumb at the interphalangeal joint (Figure).

The capsicum plaster (Johnson's $^{\mathrm{TM}}$, Perforated Capsicum Plaster, Johnson and Johnson Limited, Mumbai, India) containing active ingredient capsicum oleoresin $1 \% \mathrm{w} / \mathrm{w}$, size $11.3 \times 18 \mathrm{~cm}$, was cut into a 1 $\times \mathrm{l} \mathrm{cm}$ patch and affixed at the P6 acupoint on both forearms of subjects of Group II, $30 \mathrm{~min}$ before induction of anesthesia. Subjects in Groups I and III received a similar inactive adhesive plaster on the same point. Anesthesia was standardized and given by an anesthesiologist blinded to group assignment. At the end of the surgical procedure all patients received 2 $\mathrm{mL}$ of a drug $i v$ in specially marked syringes. Subjects of Group III received ondansetron $4 \mathrm{mg}$ (Emeset ${ }^{\circledR}$, Cipla Limited, Mumbai, India; $2 \mathrm{mg} \cdot \mathrm{mL}^{-1}$ ) while the others received normal saline. Postoperative analgesia was maintained with diclofenac $75 \mathrm{mg} i m$ every eight hours or acetaminophen $600 \mathrm{mg}$ im every six hours in patients who did not tolerate diclofenac. Plasters were removed six hours after the surgery.

The incidence of PONV was evaluated within six hours and $24 \mathrm{hr}$ after transfer to the postoperative unit by a blinded observer. Nausea and vomiting were 
TABLE I Demographic and intraoperative data for the different groups

\begin{tabular}{llll}
\hline Variable & $\begin{array}{l}\text { Group I } \\
\text { (Control) }\end{array}$ & $\begin{array}{l}\text { Group II } \\
\text { (Acustimulation) }\end{array}$ & $\begin{array}{l}\text { Group III } \\
\text { (Ondansetron) }\end{array}$ \\
\hline$n$ & 40 & 38 & 39 \\
Gender $(\mathrm{M}: \mathrm{F})$ & $14: 26$ & $12: 26$ & $12: 27$ \\
Age $(\mathrm{yr}) ;($ mean $\pm \mathrm{SD})$ & $34.47 \pm 10.08$ & $36.0 \pm 9.83$ & $35.77 \pm 9.01$ \\
Weight $(\mathrm{kg}) ;($ mean $\pm \mathrm{SD})$ & $57.2 \pm 14.02$ & $56.6 \pm 13.83$ & $58.25 \pm 13.53$ \\
History of previous PONV $n(\%)$ & $3(7.5)$ & $2(5.3)$ & $2(5.1)$ \\
History of motion sickness $n(\%)$ & $5(12.5)$ & $9(23.7)$ & $3(7.7)^{*}$ \\
Mastoidectomy $n(\%)$ & $20(50)$ & $18(47)$ & $19(49)$ \\
Tympanoplasty $n(\%)$ & $20(50)$ & $20(53)$ & $20(51)$ \\
Duration of surgery $(\min ) ;($ mean $\pm \mathrm{SD})$ & $163.23 \pm 42.5$ & $170.44 \pm 41.08$ & $168.18 \pm 43.25$ \\
Duration of anesthesia $(\min ) ;(\operatorname{mean} \pm \mathrm{SD})$ & $175.46 \pm 43.12$ & $184.81 \pm 40.8$ & $178.52 \pm 42.84$ \\
Intravenous fluids administered $(\mathrm{L}) ;(\mathrm{mean} \pm \mathrm{SD})$ & $1.5 \pm 0.4$ & $1.5 \pm 0.48$ & $1.6 \pm 0.31$ \\
\hline
\end{tabular}

$\mathrm{PONV}=$ postoperative nausea and vomiting; ${ }^{*} P=0.0514$ vs Group II.

TABLE II Frequency of PONV and requirement for rescue antiemetics

\begin{tabular}{llll}
\hline Variables & $\begin{array}{l}\text { Group I } \\
\text { (Control) }\end{array}$ & $\begin{array}{l}\text { Group II } \\
\text { (Acustimulation) }\end{array}$ & $\begin{array}{l}\text { Group III } \\
\text { (Ondansetron) }\end{array}$ \\
\hline$n$ & 40 & 38 & 39 \\
Nausea $(0-6 \mathrm{hr}) n(\%)$ & $20(50)$ & $8(21.05)^{*}$ & $11(28.21)^{*}$ \\
Vomiting $(0-6 \mathrm{hr}) n(\%)$ & $10(25)$ & $3(7.89)^{*}$ & $2(5.13)^{*}$ \\
Rescue antiemetics $(0-6 \mathrm{hr}) n(\%)$ & $11(27.5)$ & $2(5.26)^{*}$ & $3(7.69)^{*}$ \\
Nausea $(0-24 \mathrm{hr}) n(\%)$ & $22(55)$ & $19(50)$ & $20(51.28)$ \\
Vomiting $(0-24 \mathrm{hr}) n(\%)$ & $16(40)$ & $13(34.21)$ & $11(28.21)$ \\
Rescue antiemetics $(0-24 \mathrm{hr}) n(\%)$ & $15(37.5)$ & $9(23.68)$ & $7(17.95)^{*}$ \\
\hline
\end{tabular}

PONV $=$ postoperative nausea and vomiting; ${ }^{*} \mathrm{P}<0.05$ vs Group I.

recorded separately and an episode of retching was considered as vomiting. A rescue antiemetic (ondansetron $4 \mathrm{mg} i v$ ) was given to patients who experienced persisting nausea for more than five minutes, had two or more episodes of vomiting/retching or who demanded treatment for their emetic symptoms.

\section{Statistical analysis}

A sample size of 36 patients per group was determined by a priori power analysis ${ }^{8}$ on the following assumptions: a) more than $50 \%$ of the patients not receiving a prophylactic antiemetic would experience PONV, 3,9 b) prophylactic acustimulation with capsicum plaster may show a reduction of PONV by $35 \%,{ }^{7}$ c) $\alpha=0.05$ and $B=0.20$. Forty patients were selected in each group to compensate for dropouts. All data were tabulated and analyzed using Microsoft Excel 2000 (Microsoft Corporation, Redmond, WA, USA). Statistical analysis was performed using Fisher's exact test for categorical data and analysis of variance with Tukey's multiple comparison test for continuous data. $P<0.05$ was considered statistically significant.
Number needed-to-treat (NNT) was calculated by taking the reciprocal of the absolute risk reduction. It shows how many patients receiving the prophylaxis, compared with control, require an intervention before one patient will have an effective response. Confidence intervals for the NNT were calculated and expressed as suggested by Altman. ${ }^{10}$

\section{Results}

Of the 120 patients enrolled, three were subsequently excluded because they required administration of dexamethasone in the postoperative period for bronchospasm in two cases and facial nerve injury in one case. The demographic characteristics of the three groups were similar, as were history of previous PONV and motion sickness. None of the women included in the study were in their menstrual phase. There were no significant differences between the three groups with respect to duration of surgery or anesthesia, or the amount of $i v$ fluids administered (Table I).

The incidence of nausea and vomiting in the first six hours after surgery in the control group was $50 \%$. 
TABLE III Comparison of NNT of acustimulation and ondansetron for different events

\begin{tabular}{lll}
\hline Events & $\begin{array}{l}\text { Acustimulation } \\
\text { NNT }(95 \% \mathrm{CI})\end{array}$ & $\begin{array}{l}\text { Ondansetron } \\
\text { NNT }(95 \% \mathrm{CI})\end{array}$ \\
\hline Nausea $(0-6 \mathrm{hr})$ & $4(2.0-11.4)$ & $5(2.3-120.6)$ \\
Vomiting $(0-6 \mathrm{hr})$ & $6(3.0-84.7)$ & $5(2.9-21.0)$ \\
Nausea $(0-24 \mathrm{hr})$ & $20[3.7,(-5.8)]^{*}$ & $27[3.9,(-5.5)]^{*}$ \\
Vomiting $(0-24 \mathrm{hr})$ & $18[3.7,(-6.4)]^{*}$ & $9[3.1,(-11.2)]^{*}$ \\
\hline
\end{tabular}

$\mathrm{NNT}=$ number needed-to-treat; $\mathrm{CI}=$ confidence interval. ${ }^{*}$ Because the $95 \%$ CI for the absolute risk reduction extends from a negative number (treatment may harm) to a positive number (treatment may benefit), we cannot say with $95 \%$ certainty whether the prophylaxis is harmful, has no effect, or is helpful compared to control. We can only say that one of the following statements is true: the prophylaxis may be beneficial and the NNT (benefit) is greater than the first value or the prophylaxis may be harmful and the NNT (harm) is greater than the second value. ${ }^{10}$

Twenty-five percent of patients in the control group experienced vomiting. Both acustimulation and ondansetron significantly decreased these numbers. The requirement for rescue antiemetics was also significantly reduced in both treatment groups as compared to the control group (Table II).

The incidence of PONV in the first $24 \mathrm{hr}$ after surgery was not different between groups. Whereas $37.5 \%$ of cases in the control group needed treatment with rescue antiemetics, the percentage of patients requiring treatment in the acustimulation and ondansetron groups were $24 \%(P=\mathrm{NS})$ and $18 \%(P<$ 0.05 ) compared to control, respectively. One patient complained of mild irritation at the site of capsicum plaster application. No other adverse effects attributable to acustimulation or ondansetron were observed.

Table III compares the NNT of acustimulation and ondansetron for different events with their $95 \%$ confidence intervals.

\section{Discussion}

PONV is a very common complaint after middle ear surgeries $^{3,9}$ and has been attributed to both direct and indirect stimulation of the vestibular afferents. Stimulation of the auricular branch of the vagus (Arnold's nerve) may also play a role. ${ }^{11}$ There is a complex involvement of neurotransmitters and receptors in these pathways. The major ones are serotonin $\left(5-\mathrm{HT}_{3}\right)$, dopamine, histamine, opioid and muscarinic receptors. ${ }^{12}$

The present study was undertaken in a referral centre in North India and most of the subjects were of low socio-economic status. Many of them were ready to accept PONV as a part of their surgery and ignored their symptoms unless specifically questioned. This explains the rationale for inclusion of a placebo group in our study. The present study was randomized, adequately blinded, and employed a standardized anesthetic technique. A willful effort was made to avoid opioids. The patients could not afford propofol-based anesthesia, hence the most accepted practice in this part of the world was employed (thiopental and vecuronium induction; halothane and $\mathrm{N}_{2} \mathrm{O}$ maintenance). Capsicum plaster was fixed at the $\mathrm{P} 6$ points $30 \mathrm{~min}$ before giving any anesthetic drug, thereby giving adequate time for onset of action. The plaster was affixed on both forearms to avoid the question of dextrality and sinistrality. ${ }^{13}$ Ondansetron was administered at the end of surgery, as suggested by recent studies. ${ }^{4,9}$ We found that the effect of acustimulation with capsicum plaster at the P6 acupoint is comparable to $i v$ ondansetron for the first six hours after surgery.

The subjects in the control group had an incidence of PONV of $50 \%$ at six hours after the surgery. This was reduced to $21 \%$ by prophylaxis with acustimulation (NNT 4) and $28 \%$ by ondansetron (NNT 5 ). When vomiting alone was considered, the incidence of $25 \%$ in the control group was reduced to $8 \%$ and $5 \%$ by acustimulation (NNT 6) and ondansetron (NNT $5)$ respectively. The need for rescue antiemetic treatment was reduced by $80 \%$ and $72 \%$ by acustimulation and ondansetron respectively. All these changes were statistically significant and suggest a comparable efficacy of both methods. The 'NNT' indicate that one in four patients given acustimulation and one in five given ondansetron will not experience PONV.

When the incidence of PONV was compared at 24 hr after surgery, none of the groups showed any significant change (Table II). However there was a significant reduction in the requirement for rescue antiemetics in patients given ondansetron. The requirement was assessed by blinded observers based upon preset criteria, hence this should be taken as a valid outcome of antiemetic prophylaxis. ${ }^{9}$ This suggests a persisting action of ondansetron even at $24 \mathrm{hr}$.

Our findings in the ondansetron group correlate well with similar studies in the field. ${ }^{9,14}$ Although a number of investigations have evaluated acupuncture and different methods of acustimulation for the prevention of PONV, there is a paucity of published material on its role on PONV after middle ear surgery. Dundee et al., the pioneers in this area, reported a $50 \%$ reduction of PONV by invasive acupuncture at the P6 point, while non-invasive methods proved to be slightly inferior. ${ }^{13}$ Lee and Done conducted a meta-analysis on published randomized controlled trials in this field and concluded 
that nonpharmacologic techniques are effective in preventing PONV in adults in the first six hours, with an NNT of 7.6 In the present study, the efficacy of acustimulation was more marked, suggesting that stimulation of the P6 point specifically inhibits emetic stimuli from the vestibular system, although the mechanism remains obscure. The most probable mechanism of action of acustimulation is attributed to the release of endogenous opioids and modulation of other neurotransmitters in the body. ${ }^{6}$ Capsaicin, the active ingredient of capsicum plaster when applied to the skin, acts on the peripheral nerves via a mechanism similar to acupuncture. It may also have a direct action on the gastrointestinal tract, thereby inhibiting PONV. ${ }^{7}$ Acustimulation may have a more potent effect on specific neurotransmitters in the pathways linking the vestibular system to the emetic centre. The evidence that P6 stimulation reduces motion sickness ${ }^{15}$ supports this hypothesis. Although acustimulation with capsicum plaster was effective in preventing PONV in the first six hours after surgery, it did not show any benefit at $24 \mathrm{hr}$. This suggests a cessation of action of capsicum plaster before $24 \mathrm{hr}$, which is contradictory to the report by Kim et al. who demonstrated the persistent effects of capsicum plaster even after $24 \mathrm{hr}^{7}$ The reasons for this discrepancy remain unclear.

One of the obvious benefits associated with the use of capsicum plaster is the absence of unpleasant sensation associated with invasive acupuncture. ${ }^{13}$ Further, one sheet of capsicum plaster costs 9 Indian Rupee [Indian Rupee (INR) = USD \$0.20] and, when cut into $1 \times 1 \mathrm{~cm}$ squares, can be used in at least 25 patients. Thereby, the cost per person approximates INR 0.36, while ondansetron costs INR 28 per $4 \mathrm{mg}$ ampoule. Capsicum plaster is available over the counter as a treatment for musculoskeletal pain and requires no specific training for usage.

Further studies are required to determine the optimal size and duration of action of the capsicum plaster. Changing the plaster at appropriate intervals may prolong its antiemetic efficacy. In summary, the stimulation of the P6 acupoint with a capsicum plaster is a simple, inexpensive and an effective method for the prevention of PONV after middle ear surgery. Its efficacy is comparable to that of ondansetron.

\section{References}

1 Reinhart DJ, Klein KW, Schroff E. Transdermal scopolamine for the reduction of postoperative nausea in outpatient ear surgery: a double-blind, randomized study. Anesth Analg 1994; 79: 281-4.

2 Honkavaara P, Saarnivaara L, Klemola UM. Prevention of nausea and vomiting with transdermal hyoscine in adults after middle ear surgery during general anaesthesia. Br J Anaesth 1994; 73: 763-6.

3 Honkavaara P. Effect of ondansetron on nausea and vomiting after middle ear surgery during general anaesthesia. Br J Anaesth 1996; 76: 316-8.

4 Gan TJ, Meyer T, Apfel C, et al. Consensus guidelines for managing postoperative nausea and vomiting. Anesth Analg 2003; 97: 62-71.

5 Tramèr MR. Treatment of postoperative nausea and vomiting (Editorial). BMJ 2003; 327: 762-3.

6 Lee A, Done ML. The use of nonpharmacologic techniques to prevent postoperative nausea and vomiting: a meta-analysis. Anesth Analg 1999; 88: 1362-9.

7 Kim KS, Koo MS, Jeon JW, Park HS, Seung IS. Capsicum plaster at the Korean hand acupuncture point reduces postoperative nausea and vomiting after abdominal hysterectomy. Anesth Analg 2002; 95 :

\section{3-7.}

8 Campbell MJ, Julious SA, Altman DG. Estimating sample sizes for binary, ordered categorical, and continuous outcomes in two group comparisons. BMJ 1995; 311: 1145-8.

9 Sun R, Klein KW, White PF. The effect of timing of ondansetron administration in outpatients undergoing otolaryngologic surgery. Anesth Analg 1997; 84: 331-6.

10 Altman DG. Confidence intervals for the number needed to treat. BMJ 1998; 317: 1309-12.

11 Andrews PL. Physiology of nausea and vomiting. Br J Anaesth 1992; 69(Suppl. 1): 2S-19S.

12 Gilman A, Hardman JG, Limbird LE. Goodman and Gilman's The Pharmacological Basis of Therapeutics, 10th ed. New York: McGraw-Hill; 2001: 1029.

13 Dundee JW, Ghaly RG, Bill KM, Chestnutt WN, Fitzpatrick KT, Lynas AG. Effect of stimulation of the P6 antiemetic point on postoperative nausea and vomiting. Br J Anaesth 1989; 63: 612-8.

14 Tramèr MR, Reynolds DJ, Moore RA, McQuay HJ. Efficacy, dose-response, and safety of ondansetron in prevention of postoperative nausea and vomiting. A quantitative systematic review of randomized placebocontrolled trials. Anesthesiology 1997; 87: 1277-89.

15 Dundee JW, McMillan C. Positive evidence for P6 acupuncture antiemesis. Postgrad Med J 1991; 67: 417-22. 